\title{
Experimental Investigation of the Effects of Helical Roof on the Performance of Stairmand High Efficiency Cyclone
}

\author{
Aykut Karadeniz $(\mathbb{D}$ and Selami Demir \\ Department of Environmental Engineering, Faculty of Civil Engineering, Yildiz Technical University, Esenler, \\ Istanbul 34220, Turkey \\ Correspondence should be addressed to Aykut Karadeniz; aykutkaradeniz34@gmail.com
}

Received 9 July 2021; Revised 14 September 2021; Accepted 8 October 2021; Published 19 October 2021

Academic Editor: Andreas Bück

Copyright () 2021 Aykut Karadeniz and Selami Demir. This is an open access article distributed under the Creative Commons Attribution License, which permits unrestricted use, distribution, and reproduction in any medium, provided the original work is properly cited.

\begin{abstract}
Cost-effectiveness of a standard and a modified Stairmand high-efficiency type cyclone was compared at various inlet gas velocities. The modified design was obtained by replacing the roof of the standard design with a helical roof. Experiments were conducted by both standard and helical roof designs at the same operating conditions. Results showed that helical roof leads to reduced pressure drop in cyclones while having a negative impact on particle collection efficiency. Reductions in pressure drop can reach up to $30 \%$, while particle collection efficiency is reduced by up to $8 \%$ simultaneously. Overall, the treatment cost of a cyclone separator can be reduced by $14.1-20.8 \%$. Results indicated that helical roof design cyclones can be used to reduce overall treatment cost by cyclone separators.
\end{abstract}

\section{Introduction}

Cyclone separators are widely used for removing particulate matter from flue gases. Due to the simplicity in their installation and operation, they are preferred as both pretreatment and final treatment step depending on the type of dust.

Two performance parameters of a cyclone separator are pressure drop and collection efficiency. Many research studies have been dedicated to cyclones' collection efficiency and pressure drop including the study by Demir et al. $[1,2]$, and the optimum design of a cyclone separator is usually based on these operating parameters in addition to particulate loading as well as particulate characteristics. A great number of research studies pertaining to the optimization of cyclone dimensions have been performed since cyclone separators have been introduced in the beginning of twentieth century [3-15]. Over years, Stairmand high-efficiency cyclone geometry has become a standard cyclone design and has been used as a reference cyclone design in many studies [16-20].

Standard cyclones consist of four basic structural elements: the inlet channel, the body, the cone, and the outlet pipe. The inlet structure is an integrated part of the cyclone body and affects both velocity and pressure fields in the cyclone, which, in turn, affects the particle collection efficiency. Therefore, it has a direct impact on performance. Specifically, the inlet structure is the main part of the cyclone that determines flow velocity in the cyclone. For this reason, numerous research studies have been dedicated to the modification of the inlet structure and the body for optimized performance of cyclone separators. Comas et al. [21] performed experiments using cyclones with and without inlet vanes, the results of which indicated that the use of an inlet vane reduces pressure drop in cyclone, while collection efficiency for large particles remains unchanged. Yoshida et al. [22] reported results of experimental and theoretical studies on cyclones with a movable inlet guide plate, in which the cut diameter is controlled by changing the clearance of the guide plate. The experiments on a helical inlet cyclone by Gong et al. [23] revealed that helical rotation angle has a strong effect on cyclone pressure drop. The authors reported that the pressure drop increases with decreasing angle of rotation. In a later study, Huang et al. [24] reported that tubular flow laminarizers installed in the inlet 
channel resulted in increased pressure drop (by around 6\%), reduced tangential velocity component (by around $2.5 \%$ ), and reduced cut diameter of the cyclone from 2.04 to $1.89 \mu \mathrm{m}$. Misiulia et al. [25, 26] performed numerical investigations on the effects of helical roof inlets of five different angles. In these studies, the drawdown in the body roof takes place with the inlet duct totally. They reported that the cut diameter of the cyclone increases with increasing inlet angle. Besides, the pressure drop also decreases with increasing inlet angle. Jueng Charoen Sukying et al. [27] conducted a similar study and reported similar results in terms of pressure drop and particle collection efficiency. Safikhani et al. [28] performed analyses on cyclones with two and three inlets in the same circular direction and reported that three-inlet cyclone offers the highest particle collection efficiency and the lowest pressure drop. A great number of other studies can be summarized regarding the modifications on the inlet structure of cyclone separators and all of which aims at modifying the inlet structure in a systematic manner to improve cyclone performance. For example, Wasilewski and Brar [29] and Wang et al. [30] conducted studies that only changed the inlet duct angle without modifying the body structure.

As given with a number of example research studies, even a brief literature search reveals that the cyclone geometry affects the particle collection efficiency and the pressure drop in cyclone separators considerably. However, the overwhelming majority of studies deal with the effects of cyclone dimensions and the placement of its components separately on particle collection efficiency or pressure drop. Considering the fact that the selection of cyclone geometry and the cost of flue gas treatment is a function of both particle collection efficiency and pressure drop, these two operating parameters must be considered together. These operating parameters can be combined into one operating parameter called cost-effectiveness, which is a measure of the amount of energy consumed for the separation process. Unfortunately, a literature search for both operating parameters in terms of cost-effectiveness returned null, suggesting that research studies need to be carried out to determine the effects of various cyclone designs on cost of flue gas treatment.

The main purpose of this study is to provide information on how the cyclone design affects the cost of flue gas treatment with the cyclone, which is reported using a new operating parameter called cost-effectiveness. With this aim, the effects of using a helical roof on a standard cyclone design were investigated experimentally. This study presents results from the experimental study in which performances of a Stairmand high-efficiency type cyclone with standard roof and helical roof were compared. For this purpose, a helical roof structure extending from the top to the bottom of the inlet duct in the body was designed for the standard roof Stairmand high-efficiency type cyclone. The inlet structure is the same as the classical design with no changes. Both particle collection efficiency and pressure drop data from experiments were used for comparing performances of cyclone designs. The originality of this work also comes from the calculations of cost-effectiveness of cyclones, which is a numerical value of evaluation of the cost of treatment with absolute certainty and is usually omitted in most works in current literature.

\section{Materials and Methods}

2.1. Cyclone Designs. A Stairmand high-efficiency type cyclone was used as the reference cyclone design. The cyclones were of tangential inlet. The body diameter of the cyclones was $290 \mathrm{~mm}$ with total height equal to $1160 \mathrm{~mm}$. For the experiments, the helical roof cyclone was built by installing a helical structure to extend the cyclone inlet. The helical structure is an extension of the inlet which starts from the top wall of the inlet, extends downward in a rotational manner around the body wall, and completes one turn where it merges with the bottom wall of the inlet. Schematic representations of the cyclone designs are shown in Figure 1, and the dimensions are given in Table 1.

2.2. Experimental Setup. Experiments were conducted in a lab-scale cyclone separator system installed in Environmental Engineering Laboratory of Yildiz Technical University. Schematic view of the experimental setup is shown in Figure 2. The lab-scale system consists of a dust feeder, a custom-design cyclone hang, the cyclone, a radial fan, a dust bin, and digital manometers for measuring cyclone pressure drop and gas flowrate.

The experiments were organized in five repetitions for three different inlet velocities, and average values at each inlet velocity was used in evaluations. The inlet velocities were selected as $10,13.5$, and $17 \mathrm{~m} \mathrm{~s}^{-1}$ based on literature data [31-33]. The inlet velocities were calculated as the ratio of average gas flowrate to the inlet surface area. The gas flowrate measurements were performed for each inlet velocity using the method described in the study by Demir et al. [34], which employs the use of differential pressure transmitters to measure fluid flow in a closed conduit running full. Pressure drop measurements were performed between the inlet and outlet of the cyclones using a Honeywell DPTE1000D digital manometer. Overall particle collection efficiency was calculated as the ratio of the mass of particles collected in the dustbin to the mass of particles injected during a cyclone run.

Cut diameter of a cyclone separator is an important operating parameter. For the cyclones in this study, the cut diameter for each run was approximated using the following equation:

$$
\eta=\frac{1}{1+\left(d_{c} / d_{p}\right)^{2}},
$$

where $\eta$ is the overall collection efficiency, $d_{c}$ is the cut diameter, and $d_{p}$ is the median diameter of the particles injected.

Fly ash from a combustion process was used in experiments. The inlet particle concentration was set to an average of $10 \mathrm{~g} \mathrm{~m}^{-3}$ for each experiment. For efficiency calculations, particle size distribution data of injected 


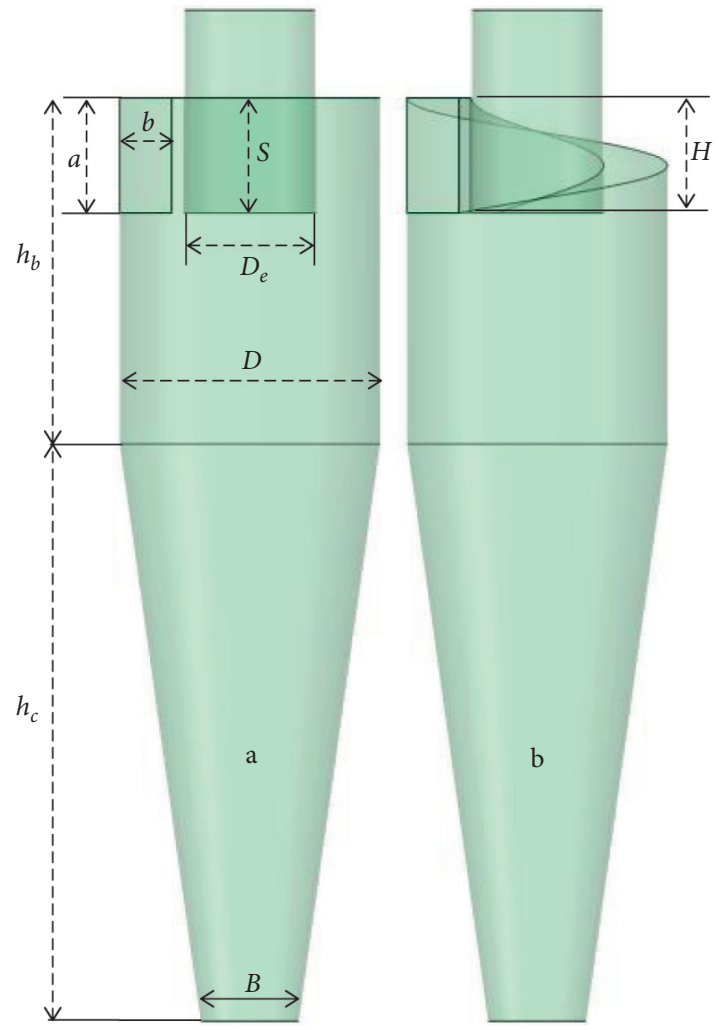

FIGURE 1: Schematic representation of (a) Stairmand high-efficiency type and (b) helical roof type cyclone.

TABLe 1: Dimensions of the cyclones.

\begin{tabular}{lccc}
\hline Parameter & Symbol & Dimension $(\mathrm{mm})$ & Ratio of dimension to body diameter* \\
\hline \multirow{2}{*}{ Inlet } & $a$ & 58 & 0.5 \\
& $b$ & 145 & 0.2 \\
\hline Body & $h_{b}$ & 435 & 1.5 \\
\hline Cone & $h_{c}$ & 725 & 2.5 \\
\hline \multirow{2}{*}{ Outlet } & $D_{e}$ & 145 & 0.5 \\
& $S$ & 145 & 0.5 \\
\hline Dustbin & $B$ & 109 & 0.375 \\
\hline Helical roof & $H$ & 145 & 0.5 \\
\hline
\end{tabular}

$D$ is the body diameter and is equal to $290 \mathrm{~mm}$.

particles were obtained by a Malvern Mastersizer Hydro $2000 \mathrm{MU}$ particle sizer. The median diameter $\left(d_{50}\right)$ was $15.22 \mu \mathrm{m}$.

2.3. Cost-Effectiveness. The concept of cost-effectiveness of a cyclone separator is defined by the amount of energy consumed for the separation process per mass of particles collected in the cyclone separator. It provides a measure of cyclone performance and allows evaluation of pressure drop and particle collection efficiency of a cyclone together, since these two operating parameters have a direct effect on the cost of separation in a cyclone separator. The amount of energy dissipated by the fan to compensate the pressure drop in the cyclone and to maintain the desired inlet velocity is simply estimated by the following formula:

$$
P=\frac{Q \rho_{g} \Delta p}{\rho_{s} \eta_{F}},
$$

where $P$ is the power requirement of the fan for compensating the pressure drop to maintain the gas flowrate (Watts), $Q$ is the volumetric flowrate of flue gas $\left(\mathrm{m}^{3} \mathrm{~s}^{-1}\right), \rho_{g}$ is the density of flue gas $\left(\mathrm{kg} \mathrm{m}^{-3}\right), \rho_{s}$ is the density of water $\left(\mathrm{kg} \mathrm{m}^{-3}\right), g$ is the gravitational acceleration $\left(9.81 \mathrm{~m} \mathrm{~s}^{-2}\right), \Delta p$ is the pressure drop in cyclone $(\mathrm{Pa})$, and $\eta_{F}$ is the overall efficiency of the fan. The amount of particles collected in the cyclone is calculated using the overall particulate collection efficiency as follows:

$$
\dot{m}=Q C \eta_{c},
$$

where $\dot{m}$ is the mass of particulate matter removed per unit time $\left(\mathrm{kg} \mathrm{s}^{-1}\right), C$ is the concentration of particulate matter 


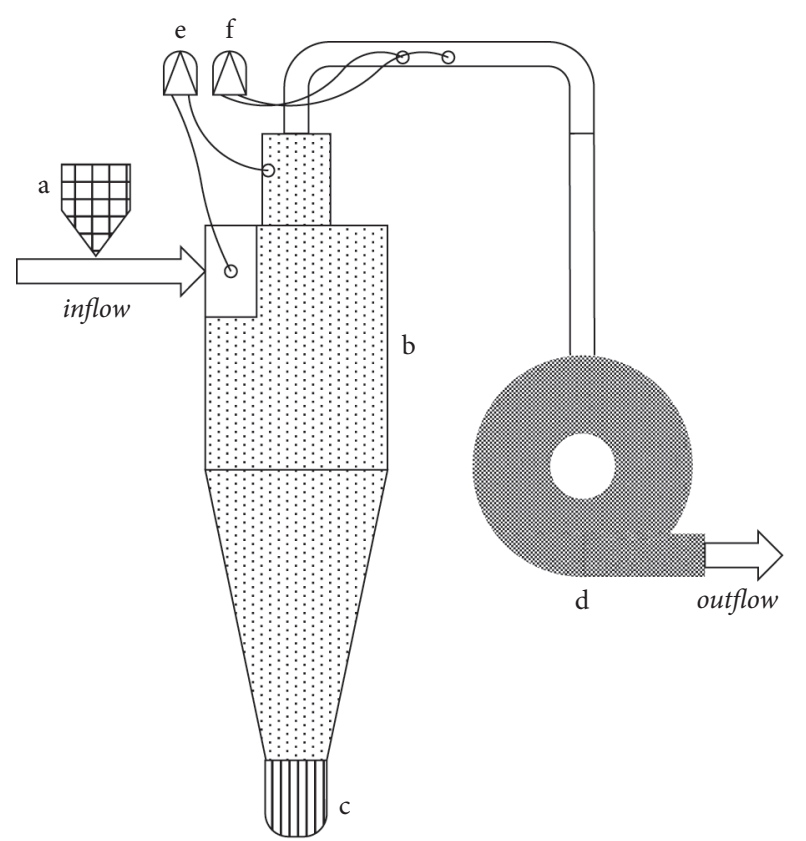
a. Dust feeder
d. Radial fan
b. Cyclone seperator
e. Digital manometer
c. Dust bin
f. Digital manometer

FIGURE 2: Schematic view of the lab-scale cyclone separator system.

injected into the cyclone, and $\eta_{c}$ is the overall collection efficiency of the cyclone. Combining equations (2) and (3), one obtains the cost-effectiveness, which is the electrical energy consumed per unit mass of particulate matter collected, equation as follows:

$$
\eta_{E}=\frac{P}{\dot{m}}
$$

where $\eta_{E}$ is the cost-effectiveness of the cyclone design (in $\mathrm{W} h \mathrm{~kg}^{-1}$ or $\mathrm{kW} h$ ton $^{-1}$ ).

\section{Results and Discussion}

3.1. Experimental Results. Measurement results of pressure drop and particle collection efficiency for both cyclone designs at each inlet velocity are shown in Figure 3. The pressure drop in Stairmand high-efficiency cyclone changed between 440 and $1180 \mathrm{~Pa}$ at inlet velocities between 10 and $17 \mathrm{~m} \mathrm{~s}^{-1}$, while the pressure drop in the modified design ranged from 345 to $872 \mathrm{~Pa}$ at the same inlet velocities. For both designs, pressure drop was confirmed to be a function of the square of the inlet velocity, as expected. The results showed that using a helical roof instead of standard roof design results in a reduced pressure drop. Although construction of a helical roof is more complicated and difficult, the positive effect reaches up to considerable levels, considering the fact that the cyclone separator works continuously during its whole life. The reduction in pressure drop by the use of helical roof ranged from $21.6 \%$ to $27.1 \%$ at various inlet velocities with an average reduction of $24.9 \%$.
The collection efficiencies showed a similar trend. In the Stairmand design, the average particle collection efficiencies ranged from $94 \%$ to $95.2 \%$ at minimum and maximum inlet velocities. In the modified design, on the other hand, the average collection efficiencies changed between $85.9 \%$ and $87.1 \%$. The results showed that the use of a helical roof results in a reduction of collection efficiency by approximately $8 \%$. In general, the helical roof design leads to a larger reduction in pressure drop than in collection efficiency. Thus, it can be considered, with further investigation, as a method of reducing operating costs.

The collection efficiency cannot be used as a universal measure of the cyclone performance since it depends on many factors other than cyclone geometry. Therefore, it is more convenient to report cut diameter, which is the aerodynamic diameter of particles that are collected with $50 \%$ efficiency, as an indicator of cyclone performance. The cut diameters for both cyclone designs were calculated using equation (1) and are given in Table 2. In the standard cyclone design, the cut diameter decreases gradually with increasing inlet velocity, meaning a higher particle collection efficiency at higher inlet velocities. On the other hand, the cut diameter of helical roof design increases with increasing inlet velocity up to $13.5 \mathrm{~m} \mathrm{~s}^{-1}$, after which the change of cut diameter was negligible. The results are given with uncertainties calculated as one standard deviation. The discrepancies between cut diameters calculated at 13.5 and $17 \mathrm{~m} \mathrm{~s}^{-1}$ for both the standard and modified cyclones were less than the uncertainties, leading to the conclusion that the differences between cut diameters at these inlet velocities were negligible.

Figure 4 shows the size distributions of the particles collected in standard and helical roof cyclones, together with the injected particles. It can be seen that the particles, which can be called PM2.5, decrease very much in the total amount after the treatment process (Figure 4(a)). This decrease was more obvious for particles $10-100 \mu \mathrm{m}$. The increases start at about $4 \mu \mathrm{m}$ and $6 \mu \mathrm{m}$ for the standard and helical roof cyclones, respectively. These results are also consistent with the calculated cut diameter values for cyclones. The frequencies of particles up to $20 \mu \mathrm{m}$ are higher in the standard roof cyclone than helical one. Then, the frequencies of coarser particles increase in the helical roof. There are reasonable trends considering that the efficiency in standard cyclone is $8 \%$ higher. Although results at $13.5 \mathrm{~m} \mathrm{~s}^{-1}$ inlet velocity are shown in Figure 4, similar trends exist at other inlet velocities.

Figure 4(b) shows the cumulative size distributions of the injected and collected particles. It is seen that the mean median diameter value of the particles collected in the standard cyclone increases compared to the injected particles. The overall collection efficiency is lower than standard cyclone in the helical one. Therefore, the grade efficiencies are lower for fine particles too, which result in increased median diameter of collected particles.

3.2. Cost-Effectiveness. As shown in Figure 3, the use of helical roof leads to drastic reductions in cyclone pressure drop, while it also leads to increased cut diameter, that is, 

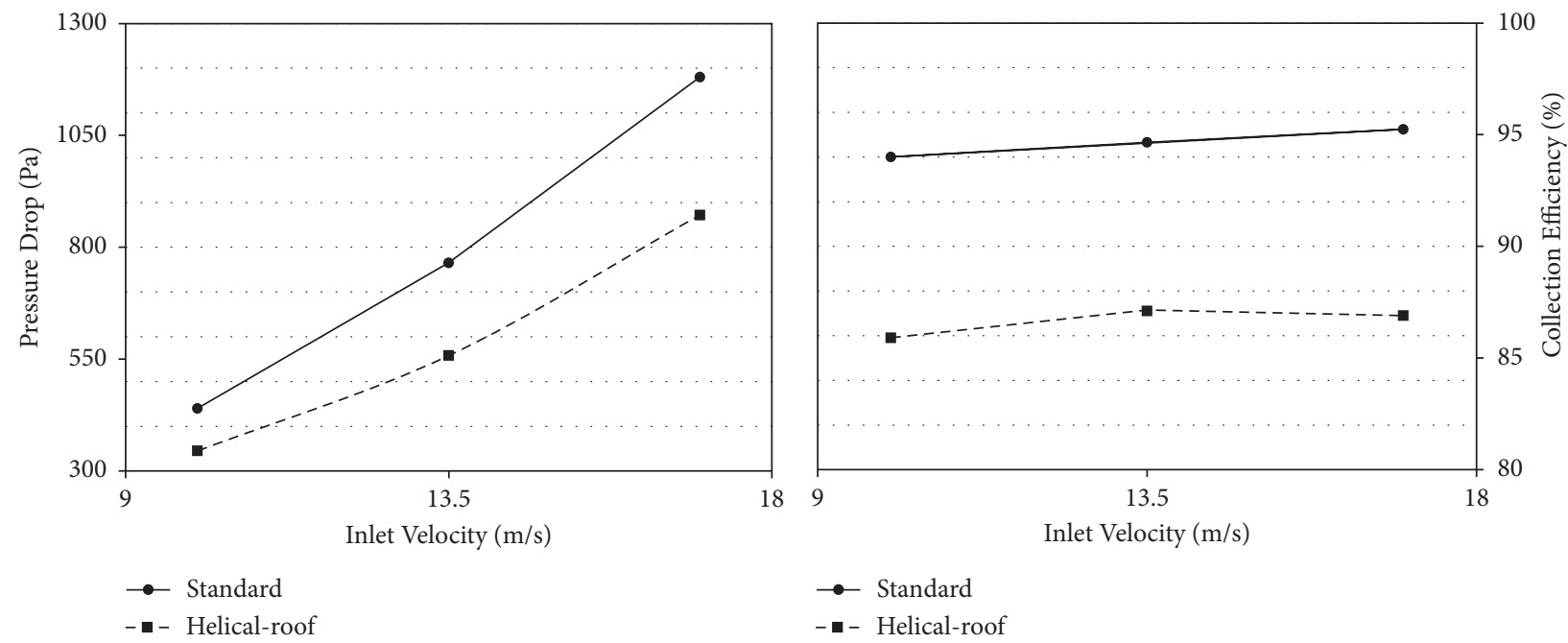

FIgURE 3: Pressure drops and collection efficiencies for inlet velocities of $10 \mathrm{~m} \mathrm{~s}^{-1}, 13.5 \mathrm{~m} \mathrm{~s}^{-1}$, and $17 \mathrm{~m} \mathrm{~s}^{-1}$.

TABle 2: Cut diameters of cyclone designs.

\begin{tabular}{lcc}
\hline Inlet velocity $\left(\mathrm{m} \mathrm{s}^{-1}\right)$ & & Cut diameters $(\mu \mathrm{m})^{*}$ \\
& Standard roof design & Helical roof design \\
\hline Minimum $\left(10 \mathrm{~m} \mathrm{~s}^{-1}\right)$ & $3.85 \pm 0.08$ & $6.17 \pm 0.06$ \\
Average $\left(13.5 \mathrm{~m} \mathrm{~s}^{-1}\right)$ & $3.62 \pm 0.05$ & $5.86 \pm 0.08$ \\
Maximum $\left(17 \mathrm{~m} \mathrm{~s}^{-1}\right)$ & $3.40 \pm 0.05$ & $5.91 \pm 0.10$ \\
\hline
\end{tabular}

*Uncertainties are given as one standard deviation.
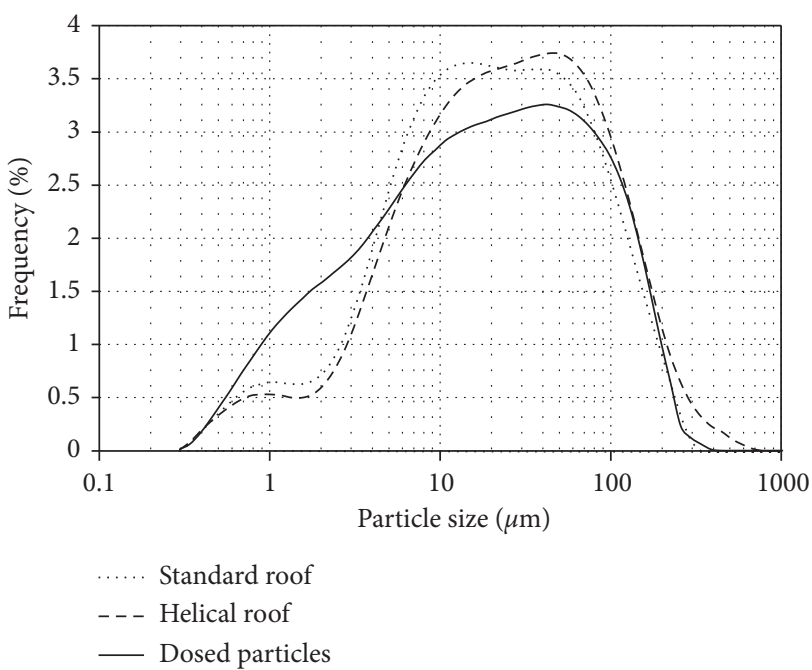

(a)

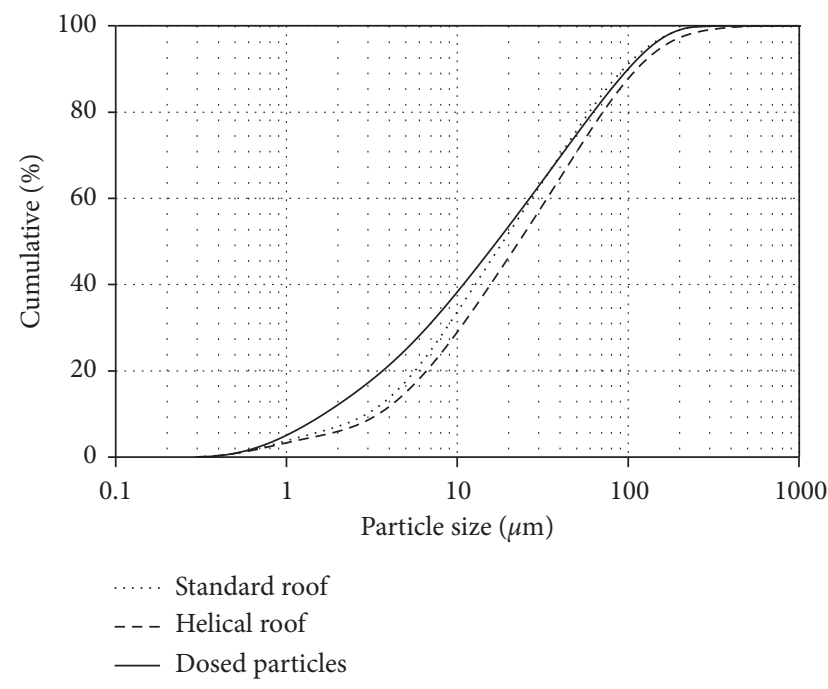

(b)

FIGURE 4: Size distributions of injected collected particles (a) frequency distribution and (b) cumulative distribution.

reduced particle collection efficiency. The calculation of costeffectiveness is a method of evaluating both performance parameters and is a measure of how much it costs to reduce particle load in the flue gas by cyclone separators. Therefore, cost-effectiveness for the standard and helical roof cyclones were calculated and compared to decide the best cyclone design for best performance, that is, the highest collection efficiency possible at the lowest pressure drop. For calculations, the inlet particle concentrations were assumed as $10 \mathrm{~g} \mathrm{~m}^{-3}$ (as equal to the average of inlet particulate matter concentrations in experiments). Rather than the total pressure drop in the system including all piping and fittings, only cyclone pressure drops, that is, the measured pressure drop between the inlet and outlet of the cyclone, were used in calculations. The results are summarized in Table 3. At the lowest inlet velocity $\left(10 \mathrm{~m} \mathrm{~s}^{-1}\right)$, the cost-effectiveness of the 
TABLE 3: Calculated cost-effectiveness for standard roof and helical roof cyclones.

\begin{tabular}{|c|c|c|c|c|c|c|}
\hline \multirow{2}{*}{ Parameters } & \multicolumn{6}{|c|}{ Cyclone designs* } \\
\hline & SD & HRD & $\mathrm{SD}$ & HRD & $\mathrm{SD}$ & HRD \\
\hline Inlet velocity & \multicolumn{2}{|c|}{10} & \multicolumn{2}{|c|}{13.5} & \multicolumn{2}{|c|}{17} \\
\hline Inlet PM load, $\mathrm{kg} \mathrm{s}^{-1}$ & \multicolumn{2}{|c|}{3.03} & \multicolumn{2}{|c|}{4.09} & \multicolumn{2}{|c|}{5.15} \\
\hline Cost-effectiveness, Wh ton ${ }^{-1} \mathrm{PM}$ & 28.4 & 24.4 & 49.0 & 38.8 & 75.1 & 60.8 \\
\hline Cost reduction by helical roof & \multicolumn{2}{|c|}{$14.1 \%$} & \multicolumn{2}{|c|}{$20.8 \%$} & \multicolumn{2}{|c|}{$19.0 \%$} \\
\hline
\end{tabular}

${ }^{*}$ Cyclone designs are SD for standard design and HRD for helical roof design.

standard cyclone was calculated as $28.4 \mathrm{Wh}$ ton $^{-1}$, while it was calculated as $24.4 \mathrm{Wh}$ ton $^{-1}$ for the modified cyclone. With the increased pressure drop and reduced particle collection efficiency by the addition of a helical roof to the Stairmand high-efficiency cyclone, it was experimentally observed that considerable energy savings was accomplished at the expense of reduced particle collection efficiency. The cost-effectiveness of the cyclone was reduced by $14.1 \%$ by the use of helical roof at $10 \mathrm{~m} \mathrm{~s}^{-1}$ of inlet velocity.

The main reason of reduced operating costs was the fact that helical roof affects pressure drop more than particle collection efficiency. At the inlet velocity of $13.5 \mathrm{~m} \mathrm{~s}^{-1}$, the reduction in pressure drop was more obvious compared to that measured at $10 \mathrm{~m} \mathrm{~s}^{-1}$ (Figure 3), which lead to a more drastic decrease in calculated cost efficiency of the helical roof cyclone. It has been experimentally determined that the cost of flue gas treatment at $13.5 \mathrm{~m} \mathrm{~s}^{-1}$ was reduced by approximately $21 \%$ by using a helical roof design. Similar findings were observed at the inlet velocity of $17 \mathrm{~m} \mathrm{~s}^{-1}$, at which the increasing trend of particle collection efficiency stopped (Table 2), and the ratio of pressure drop to inlet velocity increased more slowly. As a result, the cost savings at $17 \mathrm{~m} \mathrm{~s}^{-1}$ was calculated as $19 \%$. Overall reductions in costeffectiveness ranged from $14.1 \%$ to $20.8 \%$ at inlet velocities of 10 and $13.5 \mathrm{~m} \mathrm{~s}^{-1}$, respectively. Results indicated that the use of helical roof leads to drastic reductions in treatment costs with cyclone separators.

Considering the fact that cyclone separators can also be used as the main control device in certain cases, the reduction in particle collection efficiency exhibits a major disadvantage for the use of cyclone. On the other hand, calculated values of cost-effectiveness for modified cyclone suggested that the helical roof design can be used in cases where the cyclone separator is used as a preliminary control device, and the operating cost (pressure drop) is a more important than the particle collection efficiency.

\section{Conclusions}

In this study, effects of helical roof structure on Stairmand high-efficiency cyclone performance was investigated. For this purpose, a Stairmand high-efficiency cyclone was modified with a helical roof structure and was run at various inlet velocities. Performances of standard and helical roof designs were evaluated based on their pressure drop and particle collection efficiencies at the same conditions. Besides, cost-effectiveness was calculated to see the reduction in the cost of treatment by the modified design. Following conclusions can be withdrawn: (i) Helical roof leads to reduced pressure drop over the cyclone separator. Reduction in pressure drop can be as high as $30 \%$ at high inlet velocities.

(ii) Helical roof design has a negative influence on cyclone's cut diameter. Particle collection efficiency of a helical roof cyclone is always lower than the standard cyclone.

(iii) Since helical roof design leads to reduced particle collection efficiency, it can be considered to be a cost-effective option for pretreatment cyclones.

(iv) Cyclone separators can be designed with helical roofs for reducing overall operating costs and to run the cyclone with a higher cost-effectiveness.

\section{Data Availability}

The experimental data used to support the findings of this study are available from the corresponding author upon request.

\section{Conflicts of Interest}

The authors declare that they have no conflicts of interest.

\section{Acknowledgments}

The authors would like to acknowledge the financial support of the Scientific and Technological Research Council of Turkey (TUBITAK) under project no. 116 Y061.

\section{References}

[1] S. Demir, A. Karadeniz, and N. Manav Demir, "Artificial neural network simulation of cyclone pressure drop: selection of the best activation function in Iraq," Polish Journal of Environmental Studies, vol. 25, no. 5, pp. 1891-1899, 2016.

[2] S. Demir, A. Karadeniz, and N. Manav Demir, "Using steepness coefficient to improve artificial neural network performance for environmental modeling," Polish Journal of Environmental Studies, vol. 25, no. 4, pp. 1467-1477, 2016.

[3] C. J. Stairmand, "The design and performance of cyclone separators," Transactions of the Institution of Chemical Engineers, vol. 29, pp. 356-383, 1951.

[4] D. L. Ioza and D. Leith, "Effect of cyclone dimensions on gas flow pattern and collection efficiency," Aerosol Science \& Technology, vol. 10, no. 3, pp. 491-500, 1989.

[5] A. C. Hoffmannc, A. Van Santen, R. W. K. Allen, and R. Clift, "Effects of geometry and solid loading on the performance of gas cyclones," Powder Technology, vol. 70, no. 1, pp. 83-91, 1992. 
[6] M. Azadi, M. Azadi, and A. Mohebbi, "A CFD study of the effect of cyclone size on its performance parameters," Journal of Hazardous Materials, vol. 182, no. 1-3, pp. 835-841, 2010.

[7] K. Elsayed and C. Lacor, "Optimization of the cyclone separator geometry for minimum pressure drop using mathematical models and CFD simulations," Chemical Engineering Science, vol. 65, no. 22, pp. 6048-6058, 2010.

[8] K. Elsayed and C. Lacor, "The effect of cyclone inlet dimensions on the flow pattern and performance," Applied Mathematical Modelling, vol. 35, no. 4, pp. 1952-1968, 2011.

[9] W. Wang, P. Zhang, L. Wang, G. Chen, J. Li, and X. Li, "Structure and performance of the circumfluent cyclone," Powder Technology, vol. 200, no. 3, pp. 158-163, 2010.

[10] J. Yang, G. Sun, and C. Gao, "Effect of the inlet dimensions on the maximum-efficiency cyclone height," Separation and Purification Technology, vol. 105, no. 5, pp. 15-23, 2013.

[11] K. Elsayed, "Optimization of the cyclone separator geometry for minimum pressure drop using Co-Kriging," Powder Technology, vol. 269, pp. 409-424, 2015.

[12] O. L. Sgrott Jr., D. Noriler, V. R. Wiggers, and H. F. Meier, "Cyclone optimization by COMPLEX method and CFD simulation," Powder Technology, vol. 277, pp. 11-21, 2015.

[13] S. Demir, A. Karadeniz, and M. Aksel, "Effects of cylindrical and conical heights on pressure and velocity fields in cyclones," Powder Technology, vol. 295, pp. 209-217, 2016.

[14] P. Singh, I. Couckuyt, K. Elsayed, D. Deschrijver, and T. Dhaene, "Shape optimization of a cyclone separator using multi-objective surrogate-based optimization," Applied Mathematical Modelling, vol. 40, no. 5-6, pp. 4248-4259, 2016.

[15] O. Hamdy, M. A. Bassily, H. M. El-Batsh, and T. A. Mekhail, "Numerical study of the effect of changing the cyclone cone length on the gas flow field," Applied Mathematical Modelling, vol. 46, pp. 81-97, 2017.

[16] C. W. Haig, A. Hursthouse, S. Mcilwain, and D. Sykes, "The effect of particle agglomeration and attrition on the separation efficiency of a Stairmand cyclone," Powder Technology, vol. 258, pp. 110-124, 2014.

[17] L. S. Brar, R. P. Sharma, and K. Elsayed, "The effect of the cyclone length on the performance of Stairmand high-efficiency cyclone," Powder Technology, vol. 286, pp. 668-677, 2015.

[18] X. Sun, S. Kim, S. D. Yang, H. S. Kim, and J. Y. Yoon, "Multiobjective optimization of a Stairmand cyclone separator using response surface methodology and computational fluid dynamics," Powder Technology, vol. 320, pp. 51-65, 2017.

[19] W. I. Mazyan, A. Ahmadi, J. Brinkerhoff, H. Ahmed, and M. Hoorfar, "Enhancement of cyclone solid particle separation performance based on geometrical modification: numerical analysis," Separation and Purification Technology, vol. 191, pp. 276-285, 2018.

[20] S. Akhbarifar and M. Shirvani, "Improving cyclone efficiency for small particles," Chemical Engineering Research and Design, vol. 147, pp. 483-492, 2019.

[21] M. Comas, J. Comas, C. Chetrit, and J. Casal, "Cyclone pressure drop and efficiency with and without an inlet vane," Powder Technology, vol. 66, no. 2, pp. 143-148, 1991.

[22] H. Yoshida, T. Saeki, T. Fujioka, T. Ueda, and T. Fuyuki, "Fine particle separation by revised type Air-cyclone classifier [translated] †," KONA Powder and Particle Journal, vol. 12, pp. 178-185, 1994.

[23] G. Gong, Z. Yang, and S. Zhu, "Numerical investigation of the effect of helix angle and leaf margin on the flow pattern and the performance of the axial flow cyclone separator," Applied Mathematical Modelling, vol. 36, no. 8, pp. 3916-3930, 2012.
[24] A.-N. Huang, N. Maeda, D. Shibata et al., "Influence of a laminarizer at the inlet on the classification performance of a cyclone separator," Separation and Purification Technology, vol. 174, pp. 408-416, 2017.

[25] D. Misiulia, A. G. Andersson, and T. S. Lundström, "Effects of the inlet angle on the flow pattern and pressure drop of a cyclone with helical-roof inlet," Chemical Engineering Research and Design, vol. 102, pp. 307-321, 2015.

[26] D. Misiulia, A. G. Andersson, and T. S. Lundström, "Effects of the inlet angle on the collection efficiency of a cyclone with helical-roof inlet," Powder Technology, vol. 305, pp. 48-55, 2017.

[27] J. Juengcharoensukying, K. Poochinda, and B. Chalermsinsuwan, "Effects of cyclone vortex finder and inlet angle on solid separation using CFD simulation," Energy Procedia, vol. 138, pp. 1116-1121, 2017.

[28] H. Safikhani, J. Zamani, and M. Musa, "Numerical study of flow field in new design cyclone separators with one, two and three tangential inlets," Advanced Powder Technology, vol. 29, no. 3, pp. 611-622, 2018.

[29] M. Wasilewski and L. S. Brar, "Effect of the inlet duct angle on the performance of cyclone separators," Separation and $\mathrm{Pu}$ rification Technology, vol. 213, pp. 19-33, 2019.

[30] S. Wang, H. Li, R. Wang, X. Wang, R. Tian, and Q. Sun, "Effect of the inlet angle on the performance of a cyclone separator using CFD-DEM," Advanced Powder Technology, vol. 30, no. 2, pp. 227-239, 2019.

[31] L. Wang, M. D. Buser, C. B. Parnell, and B. W. Shaw, "Effect of air density on cyclone performance and system design," Transactions of the American Society of Agricultural Engineers, vol. 46, no. 4, pp. 1193-1201, 2003.

[32] W. B. Faulkner and B. W. Shaw, "Efficiency and pressure drop of cyclones across a range of inlet velocities," Applied Engineering in Agriculture, vol. 22, no. 1, pp. 155-161, 2006.

[33] M. Wasilewski, S. Anweiler, and M. Masiukiewicz, "Characterization of multiphase gas-solid flow and accuracy of turbulence models for lower stage cyclones used in suspension preheaters," Chinese Journal of Chemical Engineering, vol. 27, no. 7, pp. 1618-1629, 2019.

[34] S. Demir, A. Karadeniz, N. Manav Demir, and S. Duman, "An Excel VBA-based solution to pipe flow measurement problem," SIE, vol. 10, no. 3, pp. 1-16, 2018. 